\title{
Sorting out of interference in detection of endotoxins in biotherapeutic drugs
}

\author{
Ramesh Pennamareddy ${ }^{1}$, K. Prabakar ${ }^{1}$ and J. Pandiyan ${ }^{2}$ \\ ${ }^{1}$ P. G. Department of Zoology, Jamal Mohamed College (Autonomous), Tiruchirappalli; \\ ${ }^{2}$ P.G. Research Dept. of Zoology \& Wildlife Biology, AVC College (Autonomous), Mannampandal-609 305, TN, India \\ bacterialendotoxin@gmail.com
}

\begin{abstract}
The effect of varying interference factors responsible for false positive results was investigated. The interfering factors inhibiting the endotoxins in activated lymphocytes sample was sorted by heat denaturation. These activated lymphocytes are biotherapeutic drugs which are used for autologous immune enhancement therapy. The technique used for denaturation can be applied to protein samples as well, to get rid of inhibition while quantifying endotoxins.
\end{abstract}

Keywords: LAL, CSE, Bacterial Endotoxin, Endotoxin limit and Interference.

\section{Introduction}

Water is the principal source of endotoxin in parenteral products. In general, as per the United State Pharmacopeias (USP) the threshold pyrogenic dose is 5 $\mathrm{EU} / \mathrm{kg} / \mathrm{hr}$ for parenteral drugs and $0.2 \mathrm{EU} / \mathrm{kg} / \mathrm{hr}$ for intrathecal drugs. When endotoxin enters into human blood these toxins induces white blood cells (WBC) to release cytokines, such as tissue necrosis factor (TNF), interleukin-1 and interleukin-8, which mediate a complex biological response including pyrogensity, shock, coagulation and inflammation (Bang, 1956). So it is mandatory to check the presence of endotoxin level in biotherapeutic drugs before passing the product into market.

Bacterial endotoxin is one of the most potent activator of mammalian immune system. Gram negative bacterial outer membrane Lipopolysaccharide (LPS) induces a cascade of defense mechanism that is known as fever and inflammation (Good \& Lane, 1977) in incomparable fashion, for parenteral drugs administered into cerebrospinal fluid (CSF) known as intrathecal administration, $\mathrm{K}$ is reduced to $0.2 \mathrm{EU} / \mathrm{kg}$. The most common toxic route of entry of endotoxin into human system is via intrathecal administration. Endotoxins are negatively charged macromolecules as small as 20-30 $\mathrm{kDa}$, varying in size due to bacterial origin, the presence of divalent cations or biological detergents. Bacterial endotoxin is the significant pyrogen that has been identified as a contaminant in parenteral products. The $\mathrm{LAL}$ reaction with endotoxin requires $\mathrm{pH}$ neutrally and optimum levels of divalent cations. A uniform temperature of $37^{\circ} \mathrm{C}$ optimizes the rate of reaction. Most Biotherapeutic drug products require dilution with $\mathrm{LAL}$ reagent water (LRW) (Cooper, 1990) before testing to avoid interference. Testing of serum, plasma, protein sample is subjected to inhibition from serine protease inhibitors and this interference creates problems in both Biotech and research fields.

\section{Materials and methods Materials}

Limulus Amoebocyte Lysate (LAL), control standard endotoxin (CSE), LAL reagent water (LRW) were purchased from Endosafe U.S; depyrogenated $10 \times 75$ $\mathrm{mm}$ assay tubes, $16 \times 100 \mathrm{~mm}$ dilution tubes and pyrogen free micropipette tips.

Bacterial endotoxins test (BET)

The principle of bacterial endotoxin test is to detect presence of endotoxin in a given sample to which the test is applied using lysate derived from the animal Limulus polyphemus, also called as Horseshoe crab. This animal is a living fossil whose blood is blue in colour due to the presence of Hemocyanin instead of Hemoglobin. The unique property of the blood is to react with Lipopolysaccharides (LPS) present in the membrane of Gram-negative bacteria.

\section{Methods}

Procedure of $L A L$ test: Equal volume of test sample and $L A L$ reagent is added in a depyrogenated test tube of $10 \times 75 \mathrm{~mm}$ and incubated this mixture at $37 \pm 1^{\circ} \mathrm{C}$ for $60 \pm 2 \mathrm{~min}$. Then inverted the tube by $180^{\circ}$ and looked for gel formation. If a gel inside the test shows sign of integrity then it is a positive reaction which indicates presence of endotoxin in the sample. Other than this, any condition is considered as negative which indicates absence of endotoxin in the sample (lesser than the Lysate sensitivity).

Endotoxin limit: Since endotoxin is ubiquitous in nature, there has to be some safety limit to pass the product. The endotoxin limit should be such that it will not cause any harmful effects to patient. Appendix E of USFDA (United States Food and Drug Administration) gives endotoxin limits for various products. It also gives a formula through which endotoxin limit for new product can be calculated.

The formula is as follows.

Endotoxin Limit = K/ M (USP 32, 2009)

Where, K- is threshold pyrogenic dose in humans and animals. $5 \mathrm{EU} / \mathrm{kg}$ body weight for parenteral drug and $0.2 \mathrm{EU} / \mathrm{kg}$ body weight for intrathecal drug.

$\mathrm{M}$ - Maximum dose administered to a patient per $\mathrm{Kg}$ body weight per hour (Not heroic dose).

The limit formula for radiopharmaceuticals is:

$175 / \mathrm{V}$ except for intrathecally-administered products.

$14 / \mathrm{V}$ for intrathecal drugs.
Research Communication

(C)Indian Society for Education and Environment (iSee)
"Endotoxin detection in biotherapeutic drugs" http://www.indjst.org
Pennamareddy et al. Indian J.Sci.Technol. 
$V$ equals the maximum recommended dose, in $\mathrm{ml}$, at the expiration date or time. For drugs administered on a per Square Meter of Body Surface:

$5 \mathrm{EU} /[($ dose * 1.8 sq. m. $) / 70 \mathrm{Kg}]$

Product Testing: For testing products equal volume of drug (sample) and LAL reagent is taken and following tubes are prepared:

Negative Product Control (NPC)- Sample + LAL

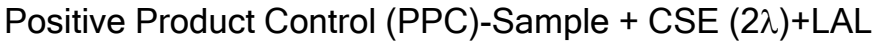

Negative Water Control (NWC)- LRW + LAL

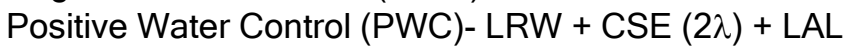

Majority of times it has been a common observation that if a product is tested directly it inhibits the LAL test and thus shows interference (van Noordwijk et al., 1997).

Interference: Interference is defined as a significant difference between the end points of positive water control and positive product control using standard endotoxin. This interference could be either inhibition wherein the recovery of endotoxin is below than the expected or enhancement wherein the recovery of endotoxin is higher than expected.

Interference may occur due to following reasons: 1) suboptimal $\mathrm{pH}$ : The optimal $\mathrm{pH}$ for $\mathrm{LAL}$ reaction is in between about 6.8 to 7.4 . If the sample is too acidic or too basic it will inhibit enzymes involved in LAL reaction. Hence it is very necessary to bring $\mathrm{pH}$ of reaction to neutral range. This can be done using $0.1 \mathrm{~N} \mathrm{HCl}$ or $0.1 \mathrm{~N}$ $\mathrm{NaOH}$ for basic and acidic product respectively. 2) Endotoxin modification: Purified endotoxin has tendency to form micelle formation which is due to hydrophilic and hydrophobic interactions between LPS and water. This aggregated endotoxin escapes LAL test. Hence to avoid such problem vortex mixing for samples is performed. 3) Container effects: Adsorption of endotoxin on tube wall causes poor recovery of endotoxin in LAL test. So it is suggested to use high quality borosilicate glass tubes because of its inert nature hence adsorption of endotoxin is least. 4) Unbalanced cations levels: Divalent cations play important role in $L A L$ reactivity and dispersion of endotoxins. $L A L$ test requires optimum concentration of $\mathrm{Ca}^{++}$and $\mathrm{Mg}^{++}$ions. If divalent cations are insufficient then $\mathrm{Ca}^{++}$and $\mathrm{Mg}^{++}$ions are added externally. 5) Protein or enzyme modification: Enzyme inactivation due to oxidants, proteolytic agents or specific inactivators will cause inhibition. 6) Non-specific LAL activation: Some molecules other than endotoxin are known to react with LAL reagent and give gel formation. This is enhancement reaction and is very rare.

\section{Subjects}

Activated lymphocyte sample which is used for autologous immune enhancement therapy for myeloid leukemia has been tested for sorting out of interference problem. $90 \%$ of interference problems are solved by just diluting the sample. But how much sample can be diluted so that it can still detect endotoxin limit is given by formula for Maximum Valid Dilution (MVD).
MVD = concentration of sample $X$ Endotoxin Limit / Lysate sensitivity

Example:

Drug : Activated Lymphocytes

Endotoxin Limit : NMT 0.25 EU/mL

Lysate sensitivity: $0.03125 \mathrm{EU} / \mathrm{mL}$

MVD = potency $\times$ E.L

$\lambda$

$=\underline{1 \mathrm{~mL} / \mathrm{mL} X 0.25 \mathrm{EU} / \mathrm{ml}}$ $0.03125 \mathrm{EU} / \mathrm{mL}$

$\mathrm{MVD}=8$

\section{Product validation:}

Product needs to be validated before start for routine testing. In validation an endotoxin standard is detected for its efficiency in a test sample as it is in LRW. This validation study consists of two different phases wherein in Phase I (Preliminary screening) involve interference testing and Phase II consists of validation of product.

The product validation significance is that it gives information on whether there are any interfering factors in the drug product to the LAL test: besides it gives an idea of the approximate levels of endotoxin content in the drug product. It also covers manufacturing of product and formulation of the product.

It is always advisable to carryout revalidation if product formulation is changed which may affect the interference pattern of the product for $L A L$ test. Also revalidation is to be conducted for any product if there is any change in manufacturing procedures or in vendor.

\section{Results and discussions \\ Phase I: Preliminary screening / interference study}

In this two identical series of product dilutions (two-fold dilutions), one spiked with $2 \lambda$, and one left unspiked. The result of Phase I will reveal the non-interfering dilution (NID) of the product, which is used for the actual validation (Phase II). The non-interfering dilution (NID) is the first set of PPC that shows a gel.

Example:

Drug : Activated Lymphocytes

Endotoxin Limit : NMT $0.25 \mathrm{EU} / \mathrm{mg}$

Lysate sensitivity: $0.03125 \mathrm{EU} / \mathrm{mL}$

MVD = potency $\times \mathrm{E} . \mathrm{L}$

$\lambda$

$=\underline{1 \mathrm{~mL} / \mathrm{mL} X 0.25 \mathrm{EU} / \mathrm{ml}}$ $0.03125 \mathrm{EU} / \mathrm{mL}$

MVD $=8$

Table 1 shows that there is inhibition up to 1:8 (MVD). Due to Inhibition, LAL is unable to detect the endotoxins even in spiked sample. After analyzing the sample using different procedures, finally In order to sort out this inhibition problem then the activated sample is heated at $55^{\circ} \mathrm{C}$ for $15 \mathrm{~min}$ to coagulate the proteins in the sample and this heat denaturation technique is applicable to all protein samples. The denaturation won't affect the endotoxin because endotoxins can be denatured at $250^{\circ} \mathrm{C}$ for 30 minutes as per USP.
Research Communication

CIndian Society for Education and Environment (iSee)
"Endotoxin detection in biotherapeutic drugs" http://www.indjst.org
Pennamareddy et al. Indian J.Sci.Technol. 
Table 1. Inhibition assay at different dilution (1:1-1.8)(-- not detectable)

\begin{tabular}{|c|c|c|c|c|}
\hline Sample Dilution & $1: 1$ & $1: 2$ & $1: 4$ & $1: 8$ \\
\hline Unspiked & -- & -- & -- & -- \\
\hline Spiked & -- & -- & -- & -- \\
\hline
\end{tabular}

Assay results after Heat denaturation of the sample is presented in Table 2.

Table 2. Assay results after heat denaturation of the sample

\begin{tabular}{|c|c|c|c|c|}
\hline Sample dilution & $1: 1$ & $1: 2$ & $1: 4$ & $1: 8$ \\
\hline Unspiked & -- & ++ & -- & -- \\
\hline Spiked & -- & ++ & ++ & ++ \\
\hline
\end{tabular}

There is inhibition up to $1: 1$ dilution and the spike recovery at 1:2 dilutions onwards. Therefore the NID is 1 : 2 . It is advisable to validate the product at not less than $1: 4$ dilution to take care of any batch to batch variation during regular production. So 1: 4 dilution is chosen for product validation.

\section{Phase II: Validation of product}

For validation, test and compare two identical series of endotoxin dilutions bracketing $\lambda$; One prepared in LRW and another prepared in product diluted to the proposed test dilution. Here dilution selected for validation is 1:4. (Hot spike method).

Table 3. Endotoxin/product (negative product control: --; geometric mean $=0.03 \mathrm{EU} / \mathrm{ml}$ )

\begin{tabular}{|c|c|c|c|c|}
\multicolumn{5}{|c}{ geometric mean $=0.03 \mathrm{EU} / \mathrm{ml})$} \\
\hline \multirow{2}{*}{ Replicates } & $\begin{array}{c}0.0625 \\
\mathrm{EU} / \mathrm{mL}\end{array}$ & $\begin{array}{c}0.03125 \\
\mathrm{EU} / \mathrm{mL}\end{array}$ & $\begin{array}{c}0.015 \\
\mathrm{EU} / \mathrm{mL}\end{array}$ & $\begin{array}{c}0.007 \\
\mathrm{EU} / \mathrm{mL}\end{array}$ \\
\hline 1 & + & + & - & - \\
\hline 2 & + & + & - & - \\
\hline 3 & + & + & - & - \\
\hline 4 & + & + & - & - \\
\hline
\end{tabular}

Example of results is presented in Table 3 \& 4 .

Successful validation requires that both series confirm label claim (Geometric mean) within +/- one two-fold dilution. Validation is conducted at this dilution on three batches of product.

Table 4. Endotoxin/LRW Blank --; (geometric mean $=0.03$

\begin{tabular}{|c|c|c|c|c|}
\hline Replicates & 0.0625 \\
& EU/mL & $\begin{array}{c}0.03125 \\
\mathrm{EU} / \mathrm{mL}\end{array}$ & $\begin{array}{c}0.015 \\
\mathrm{EU} / \mathrm{mL}\end{array}$ & $\begin{array}{c}0.007 \\
\mathrm{EU} / \mathrm{mL}\end{array}$ \\
\hline 1 & + & + & -- & -- \\
\hline 2 & + & + & -- & -- \\
\hline 3 & + & + & -- & -- \\
\hline 4 & + & + & -- & -- \\
\hline
\end{tabular}

\section{BET applications}

Large Volume Parenterals (LVPs), multipleingredient drugs, Small Volume Parenterals (SVPs), Radiopharmaceuticals, biologicals, water system validation, validation of dry heat sterilizer and medical devices (Pearson et al., 1991).

\section{References}

1. Bang FB (1956) A bacterial disease of Limulus polyphemus. Bull. Johns Hopkins Hosp. 58, 325351.

2. Cooper JF (1990) Resolving LAL test interferences. J. Parenteral Sci. Tech. 44, 13-15.
Vol.2 No. 11 (Nov. 2009)

ISSN: 0974- 6846

3. FDA LAL Test Guideline (2009) Bacterial endotoxin test. USP 32 (85).

4. Mc Closky WT, Prince CW, Van Winkle WJ, Welch H and Calvery HO (1943) Results of first USP collaborative study of pyrogens. J. Am. Pharm. Assoc. 32, 69-73.

5. Good CM and Lane Jr. HE (1977) The biochemistry of pyrogens. Bull. Parenter. Drug Assoc. 31, 116-120.

6. Pearson FC (1991) Limulus amebocyte lysate testing: comparative methods and reagents. In: Sterile Pharmaceutical Manufacturing: Applications for the1990s. Eds. Groves MJ, Olson WP \& Anisfe1d MH, Vo1.2. Interpharm Press. pp: 185-197.

7. Sullivan JD and Watson SW (1975) Purification and properties of the clotting enzyme from Limulus lysate. Biochem. Biophys. Res. Commun. 66, 848-855.

8. USP 24-NF (1999) Bacterial Endotoxins Test. $2^{\text {nd }}$ Supplement, 85. The USP Convention, Rockville, MD. pp: 2875-2879.

9. van Noordwijk $J$ and DeJong $Y$ (1977) Comparison of the LAL test with the rabbit test: false positives and false negatives. Dev. Boil. Stand. 34, 39-43.
Pennamareddy et al. Indian J.Sci.Technol. 